\title{
Changes in Edaphic Gradients across Forest-Land Use Margins in an Isolated Rainforest Remnant in the Knuckles Range, Sri Lanka
}

\author{
Sripal D.D.N. ${ }^{1 *}$, Gunatilleke I.A.U.N. ${ }^{2}$, Gunaratne A.M.T.A. ${ }^{2}$ and Madawala H.M.S.P. ${ }^{2}$ \\ ${ }^{1}$ Postgraduate Institute of Science, University of Peradeniya, Peradeniya, Sri Lanka \\ ${ }^{2}$ Department of Botany, Faculty of Science, University of Peradeniya, Peradeniya, Sri Lanka \\ *dilpanaradasripal@yahoo.com
}

\begin{abstract}
Forest fragmentation is been identified as one of the factors that initiate forest degradation. The size of the forest patch and its bordering landscape decide the severity of disturbances to these forest patches. Moraella forest, a lowland rainforest remnant located in the Knuckles Range, is bordered by many landuse types. The present study was aimed at investigating the edaphic gradients across the forest edge bordered by different forest-landuse types viz., Pinus, grassland, tea plantation and a scrubland. Seven linear quadrates (3 m x $12 \mathrm{~m})$ were laid in 3 transects totaling 21 quadrates per forest-landuse category. The quadrates were positioned parallel to the forest-landuse edge and at different distances away from the edge $(0,10$ and 30 $\mathrm{m}$ towards the forest interior; 10,30 and $50 \mathrm{~m}$ towards the bordering landuse type). Soil samples (up to a depth of $5 \mathrm{~cm}$ ) were collected from each quadrate and were bulked together to make a representative sample for each distance and per transect. The samples were analysed for available cations ( $\mathrm{Ca}, \mathrm{Mg}$ and $\mathrm{K}$ ), available $\mathrm{P}$, total $\mathrm{C}$ and $\mathrm{N}$, $\mathrm{pH}$ using standard methods. Data was analysed using General Linear Model (GLM) taking distance as a fixed factor in Minitab 14.1.
\end{abstract}

The results showed that soil $\mathrm{Mg}$ and available $\mathrm{P}$ showed significant differences between distances in forest-landuse transects while $\mathrm{Ca}$ and $\mathrm{Mg}$ concentrations showed significant differences between landuse types. Pair-wise comparisons revealed that the soil $\mathrm{Mg}$ in the forest interior was higher than that of the bordering landuse, irrespective of the type of the landuse. Available soil $\mathrm{P}$ also showed a similar increase towards the forest interior. This is possibly due to higher mycorrhizal-dependent tree species found in the forest than that in the bordering landuse types. Other chemical parameters did not show any significant differences along these transects. Soil $\mathrm{Ca}$ in the scrubland and small-holder tea plantation showed significantly higher concentrations compared to Pinus and it was evident in both in the forest interior as well as in the open landuse. Higher Ca levels in the small-holder tea plantation may be due to the use of lime to reduce soil acidity. The forest-scrubland soils showed significantly higher $\mathrm{Mg}$ levels than that of other three landuse categories. However, soil $\mathrm{C}, \mathrm{N}$ and $\mathrm{pH}$ showed no significant differences across these forest-landuse transects. The present results suggest that edaphic gradients do exist across forest-landuse transects, but with some soil parameters. The bordering landuse type and its management practices may have some impacts on creating such gradients.

Keywords: Forest remnants, Forest-landuse edge, Moraella forest, Edaphic gradient, Forest fragmentation 